\title{
POSTBUCKLING AND GROWTH OF DELAMINATIONS IN COMPOSITE PLATES SUBJECTED TO AXIAL COMPRESSION
}

AIAA 2002-1746

\author{
James R. Reeder ${ }^{*}$ \\ NASA Langley Research Center \\ Hampton, VA 23681 \\ j.r.reeder@larc.nasa.gov \\ Prasad B. Chunchu ${ }^{\ddagger}$ \\ Eagle Aeronautics \\ Hampton, VA
}

\section{$\underline{\text { Abstract }}$}

The postbuckling response and growth of circular delaminations in flat and curved plates are investigated as part of a study to identify the criticality of delamination locations through the laminate thickness. The experimental results from tests on delaminated plates are compared with finite element analysis results generated using shell models. The analytical prediction of delamination growth is obtained by assessing the strain energy release rate results from the finite element model and comparing them to a mixed-mode fracture toughness failure criterion. The analytical results for onset of delamination growth compare well with experimental results generated using a 3-dimensional displacement visualization system. The record of delamination progression measured in this study has resulted in a fully 3-dimensional test case with which progressive failure models can be validated.

\section{Introduction}

Delamination is a primary failure mode for laminated composite materials. Delaminations can occur due to many factors such as manufacturing flaws, freeedge stresses, and impact damage. In many cases, the delamination will not grow and will result in only a small stiffness degradation to the structure. This is

\footnotetext{
*Research Engineer, Mechanics and Durability Branch.

${ }^{\dagger}$ Research Engineer.

${ }^{\ddagger}$ Senior Scientist.

${ }^{\S}$ Head, Mechanics and Durability Branch. Associate Fellow, AIAA.
}

Copyright (C) 2002 by the American Institute of Aeronautics and Astronautics, Inc. No copyright is asserted in the United States under Title 17, U.S. Code. The U.S. Government has a royalty-free license to exercise all rights under the copyright clamed herein for Governmental purposes. All other rights are reserved by the copyright owner.

\author{
Kyongchan Song ${ }^{\dagger}$ \\ Swales Aerospace \\ Hampton, VA
}

\author{
Damodar R. Ambur ${ }^{\S}$ \\ NASA Langley Research Center \\ Hampton, VA
}

especially true in tension load cases. In compression, delaminations can allow a sublaminate of the composite to buckle, which further drives the delamination growth. This failure mechanism, if not accounted for properly, can lead to uncontrolled delamination growth and premature failure of the structure. Therefore, predicting delamination growth can be critical to determining structural integrity. Several studies have investigated the growth of a postbuckled delamination $^{1-6}$. These studies involved buckling of delaminations in flat plates and in shells with axisymmetric delaminations. No studies are reported that validate, with experimental results, an analysis of a fully 3-dimensional delamination problem involving laminate curvature, buckling and subsequent delamination growth.

A verified analysis of delamination growth using simple modeling techniques would allow delamination growth predictions in more complex structures and in more routine analyses. Such a methodology could also be extended to progressive delamination growth predictions in an automated manner. Critical locations where delaminations would grow to failure when initiated could then be identified so that this type of damage would be avoided.

The strain energy release rate (SERR) that drives delamination growth is normally determined using a finite element (FE) analysis. The virtual crack closure technique ${ }^{7-9}$ is a simple way of extracting SERR values from FE results and allows the total SERR value to be divided into the three loading mode components: opening, sliding shear, and tearing shear. The composite material can either be modeled with shell elements or three-dimensional (3-D) brick elements. The 3-D brick element models have been shown to be more accurate especially in dividing the strain energy release rate into individual modes ${ }^{9-11}$. Others have shown reasonably good agreement between results obtained from shell element and 3-D element models with only a moderate difference in mixed-mode ratio 
due to shell element modeling ${ }^{8,9}$. The 3-D element models can result in extremely large analyses, especially when investigating structural response. In 3-D models, the in-plane element size must often be quite small because the in-plane dimension must be comparable to the small dimension in the thickness direction. This is not a problem for the shell element models, so the inplane element sizes can be much larger. Shell element models can also be smaller because only one node is needed through the thickness of the model except in delaminated regions where two are needed. When modeling a simple test specimen, either shell or 3-D element models can be performed, but for models of larger structures or for progressive models that must be solved repeatedly, the size of a 3-D element model can quickly make a problem intractable. Shell element models may be less accurate but they can be much more practical for investigation of structural problems.

The objective of this paper is to study the influence of circular delaminations on the strength of flat and curved plates subjected to axial compression loading. Two cases with delaminations placed at different interfaces within the laminate were studied. Shell element modeling is used in conjunction with a delamination growth criterion based on mixed-mode fracture toughness to determine the threshold for postbuckled delamination growth.

\section{Finite Element Analysis}

Finite element models of the specimen to be tested in this study were created with standard shell elements (S4 elements) in the ABAQUS ${ }^{12}$ code. The $114-\mathrm{mm} x$ $228-\mathrm{mm}$ ( 9 in. $x 4.5$ in.) models were either flat or cylindrical with a centrally located 64-mm-diameter $(2.5$ in.) delamination. A representative finite element model of the test specimen is shown in Figure 1. The loading of the panel was in the direction of the axis of the cylinder or along the long axis of the flat panel. Two cylindrical panels were tested: one slightly curved (760$\mathrm{mm}$ radius) and the other more curved (380-mm radius). These three specimen types will be referred to as flat, slightly curved and more curved, respectively, throughout this paper.

The panels were made of AS4/3501-6 graphite/epoxy composite material system and typical lamina properties for this material were used in the model (see Table 1). The laminate stacking sequence was $\left[(\mp 45 / 90 / 0)_{2} / \mp 60 / \mp 15\right]_{\mathrm{s}}$ which is representative of the skin structure for a reusable launch vehicle application $^{13}$. Each specimen in this study contained a circular delamination at one of two interfaces. Interface 1 was between the $4^{\text {th }}$ and $5^{\text {th }}$ plies which put the delamination at the interface between the $0^{\circ}$ and $+45^{\circ}$ plies. Plies are counted from the convex surface of the plate. Interface 2 was between the $5^{\text {th }}$ and $6^{\text {th }}$ ply which
Applied load

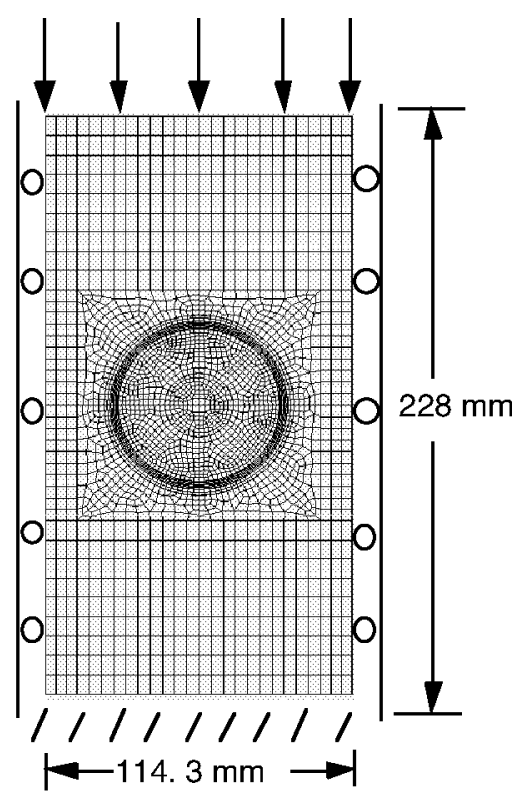

Figure 1. Finite element model.

put the delamination between the $+45^{\circ}$ and $-45^{\circ}$ plies. In the delaminated region, two superimposed shell elements were used to model the two sublaminates created by the delamination. To avoid over constraint of cross-section rotations at the delamination front, the region modeled by two shell elements was extended $3.2-\mathrm{mm}$ ( 5 nodes) beyond the circular delaminated region. Multipoint constraints on displacement held the two superimposed shell elements together in the region where no delamination exists. To prevent penetration of elements in the delaminated region, contact boundary conditions were applied. The element size along the front of the circular delamination was $1.9-\mathrm{mm}$ in the circumferential directions and $0.5-\mathrm{mm}$ in the radial direction.

The critical load for sublaminate buckling in the panel was predicted using a linear buckling analysis for the first eigenvalue. To predict the postbuckling response, a nonlinear analysis was used. The nonlinear analysis included a small initial imperfection to initiate sublaminate buckling. The magnitude of the

Table 1. Properties for AS4/3501-6 graphite/epoxy material

\begin{tabular}{cr}
\hline \hline Property & Value \\
\hline $\mathrm{E}_{11}(\mathrm{MPa})$ & 127,557 \\
$\mathrm{E}_{22}(\mathrm{MPa})$ & 11,375 \\
$\mathrm{G}_{12}(\mathrm{MPa})$ & 5,998 \\
$\mathrm{v}_{12}$ & 0.3 \\
Ply Thickness $(\mathrm{mm})$ & 0.135 \\
\hline \hline
\end{tabular}




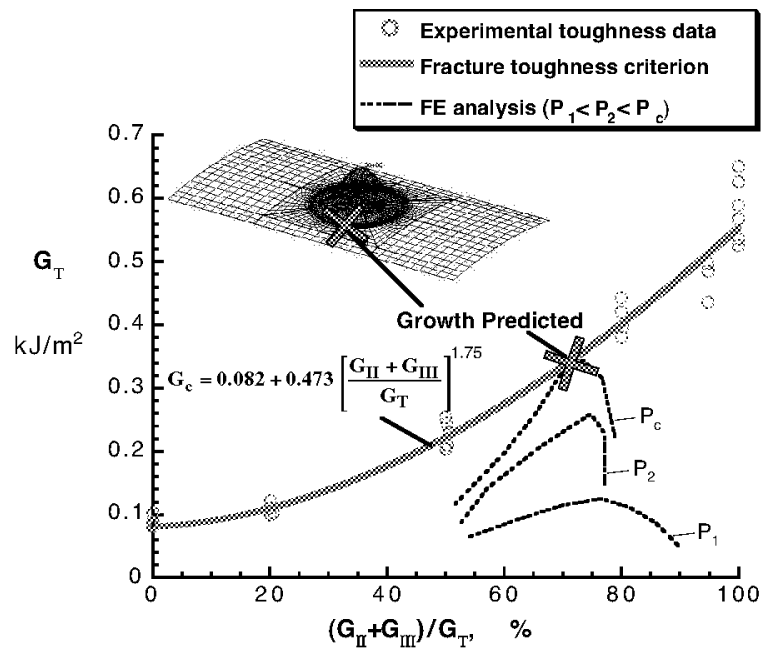

Figure 2. Mixed-mode failure criterion for AS4/3501-6 material.

imperfection was $0.1-\mathrm{mm}$ ( $5 \%$ of the model thickness), and the shape of the imperfection corresponded to the first buckling mode of the panel. The strain energy release rate was found to be insensitive to further increase in the imperfection magnitude. The virtual crack closure technique ${ }^{7,9}$ was used to determine strain energy release rate along the delamination front. The use of the virtual crack closure technique allowed the strain energy release rate to be separated into the three components: Mode I (opening), Mode II (sliding shear) and Mode III (tearing shear).

To predict the initiation of delamination growth (both load and location along the delamination boundary), a mixed-mode fracture toughness failure criterion was used. A mixed-mode criterion is important because the toughness of composite materials can vary significantly with the loading mode. Fully 3-D problems contain components of all three fracture modes. Since no method currently exists for measuring fracture toughness where Modes I, II and III are varied independently, the failure criterion was obtained as a curve fit through data from the mixed-mode bending test ${ }^{14}$ which can be used to apply Mode I and Mode II in various proportions. Experimental data was taken from Reference 15 , but the raw data was reanalyzed to be consistent with the data analysis procedure in the recently published ASTM D6671-01 test standard to obtain the toughness data presented in Figure 2. A mixed-mode failure criterion was fit through the data in Figure 2. This failure criterion was suggested by Gong and Benszeggagh ${ }^{16}$ and was found to fit the data well. FE analysis calculations of SERR were compared with the failure criterion to determine if delamination growth occurs. To compare $\mathrm{FE}$ analysis results which contained a Mode III component of loading to the toughness data, the Mode III component was combined with the Mode II to define the mixed-mode ratio: $\left(\mathrm{G}_{\mathrm{II}}+\mathrm{G}_{\mathrm{III}}\right) / \mathrm{G}_{\mathrm{T}}$. As the loading on the model was increased $\left(\mathrm{P}_{1} \rightarrow \mathrm{P}_{2}\right)$, the strain energy release rate increased, as shown in Figure 4. Because this was a nonlinear analysis, the mixed mode ratio at a given point can change as the loading increases. The loading on the model was increased until the critical load $\left(\mathrm{P}_{\mathrm{c}}\right)$ was reached where the analytical strain energy release rate curve intersected the mixed-mode toughness curve. The location along the delamination boundary corresponding to the intersection point was the point where the delamination growth was predicted to initiate. This procedure was used to determine the critical load and location for delamination growth in all panels.

\section{Experimental Investigation}

Three replicate tests were conducted with six different test configurations. The six test configurations combined three panel curvatures and two different delamination locations within the laminate stacking sequence. The three panel curvatures included a flat panel, a slightly curved cylindrical shell that had a $760-\mathrm{mm}$. radius (30 in.), and a more curved cylindrical shell that had a $380-$ $\mathrm{mm}$. radius (15 in.). The specimens were tested in a NASA ST $-4^{17}$ compression test fixture that had been modified to accept curved specimen. A drawing of the test specimen is shown in Figure 3 . The test specimens measured $123-\mathrm{mm} \times 254-\mathrm{mm}$ ( 5 in. $\times 10$ in.). When placed in the test fixture which produced clamped support at the loading ends and knife edge supports along the unloaded edges, the unsupported panel dimension measured $114-\mathrm{mm} \times 229-\mathrm{mm}$. (4.5 in. $x 9$ in.). The axis of the cylinder and the loading

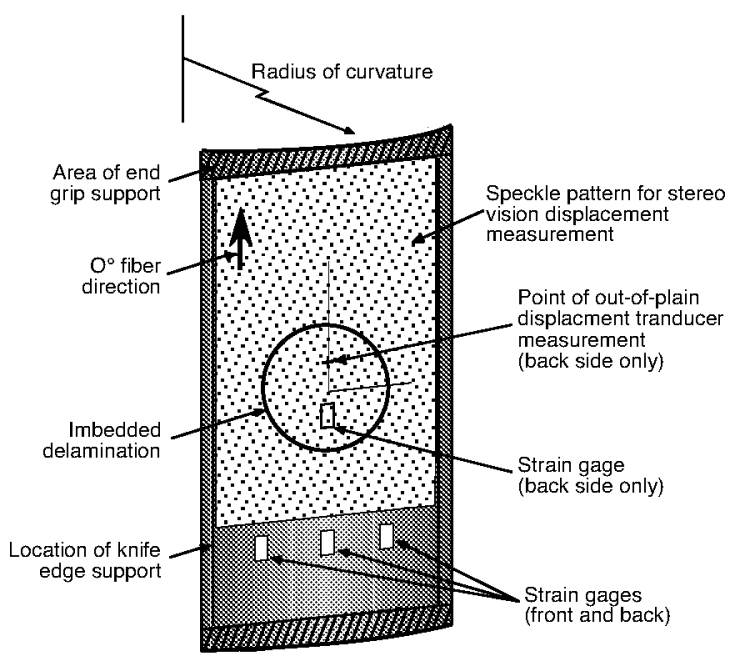

Figure 3. Diagram of test specimen. 
direction were always along the long axis of the panel.

Each panel was fabricated from AS4/3501-6 graphite-epoxy prepreg into a $\left[(\mp 45 / 90 / 0)_{2} / \mp 60 / \mp 15\right]_{\mathrm{s}}$ laminate that was autoclave cured. The layup of the specimens varied slightly in that the more curved specimens where laid up on a concave tool while the slightly curved specimens were laid up on a convex tool. Since the imbedded delamination was always located next to the convex surface of the laminate, the delaminated region in the slightly curved specimen was next to the bag side of the laminate and, therefore, would be slightly more irregular in shape. The flat specimen was laid up with the delamination close to the tool side, and so it would be more regular in shape, similar to the more curved specimen.

A 64-mm.-diameter (2.5 in.) delamination was introduced during manufacturing by implanting a 13$\mu \mathrm{m}$-thick Teflon sheet into the center of each panel. The delamination was placed either between the $4^{\text {th }}$ and $5^{\text {th }}$ plies (interface 1 ) or between the $5^{\text {th }}$ and $6^{\text {th }}$ plies (interface 2). The insert was always placed near the convex surface of the curved specimen. A C-scan was taken of each specimen to non-destructively ensure the location of the delaminations.

During the test, applied load and end-shortening displacements were measured. Strain data from the seven strain gages shown in Figure 3 were also recorded. To align the test specimen, the specimen was loaded to $4.4 \mathrm{kN}(1000 \mathrm{lb})$ and the alignment of the loading platen was adjusted until all the strain gage readings were approximately the same. A stereo imaging system was used, as shown in Figure 4, to measure the full-field 3-D deformation of the specimen. This system, called the VIC3D ${ }^{18}$ system, uses the images from two cameras to triangulate on the position of points in a random speckle pattern on the specimen surface. The speckle pattern was printed on a vinyl sheet, which was adhered to the surface of the specimen closer to the delamination insert. Images were taken from the stereo imaging system every 5 seconds $(\sim 0.4-\mathrm{kN}$ of loading increments). These measurements provided a quantitative full-field deformation record of the buckling delamination.

The test was stopped after both sublaminate buckling of the delamination and some delamination growth had occurred. Since the full-field measurements could not be visualized during the test when data was being taken at the desired rate, it was determined that the tests could be stopped when the reading from any one strain gage reached $4000 \mu \varepsilon$ for the flat panel and $5000 \mu \varepsilon$ for the curved panel. This arbitrary cut off point provided adequate delamination growth and prevented delamination growth all the way to the edge supports.

The process for determining the initiation and growth of the delamination from the full-field deformation data is illustrated in Figure 5. First the out-of-plane deformation pattern was determined, which resembles an oval as shown in Figure 5(a). Out-of-plane displacement data was taken along the major axis of this oval and plotted against the distance along the major axis. At or near the minimum value of the out-of-plane deformation, a noticeable shift in the slope of the curve was consistently present. Although this point was not believed to exactly correspond to the delamination front position, a given shift in this point from one load level to the next was believed to correspond to the same shift in the position of the delamination front. Since the original size of the delamination was known, the size of the delamination at an imposed load level could be determined by adding the shift in position to the original size.

The final size of the delamination was also determined using an enhanced X-ray technique. To

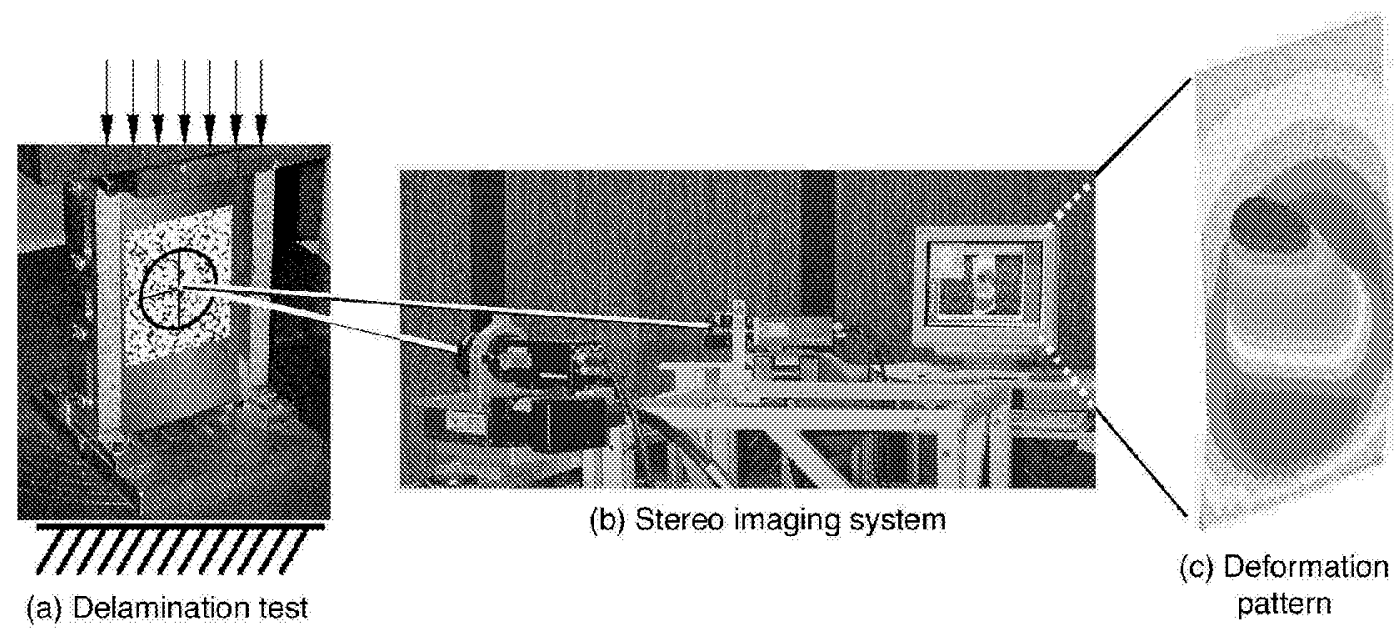

Figure 4. Test setup with stereo imaging system. 


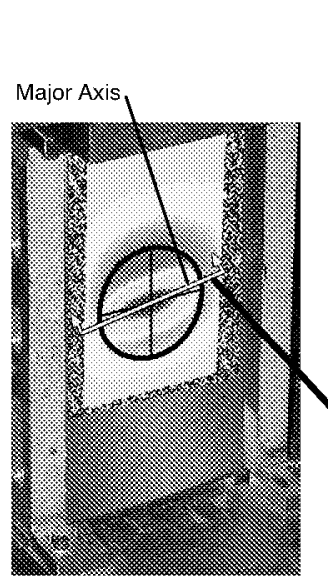

(a) Major axis for oval-shaped deformation.

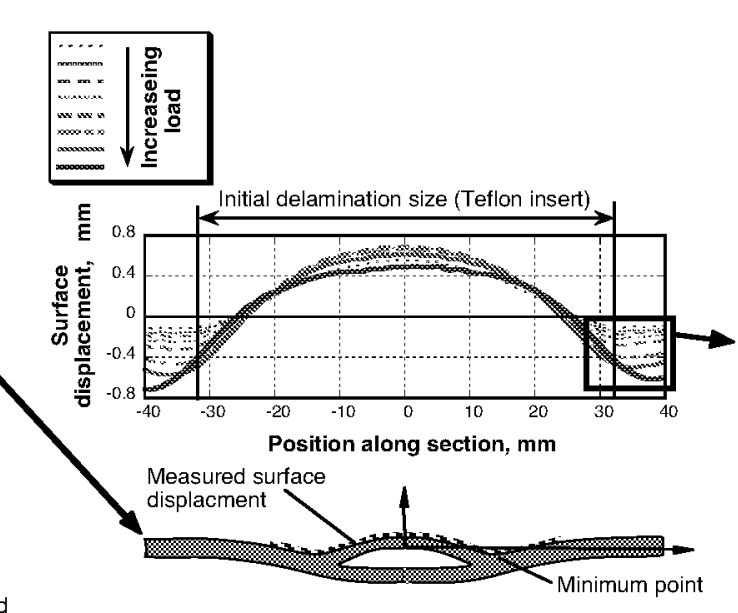

(b) Out of plane displacement contours for increasing load.

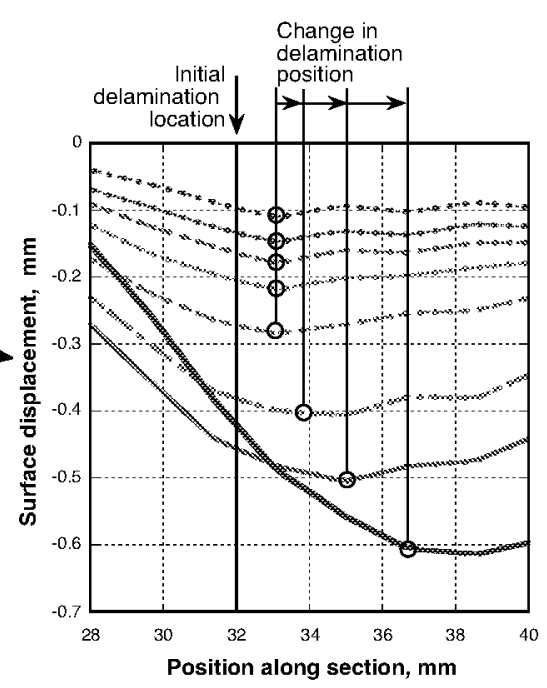

(c) Shift in delamination position.

Figure 5. Approach for delamination growth determination.

insert the die penetrant, a $0.8-\mathrm{mm}(1 / 32$ in.) diameter hole was drilled at the center of the delamination from the back side of the specimen before the specimen was tested. The hole was small and far removed from the delamination front so it was not believed to affect the delamination growth. After the test, the die penetrant made of zinc iodide, photographic wetting agent and isopropyl alcohol was worked into the delamination and an X-ray photograph was taken.

\section{$\underline{\text { Results and Discussion }}$}

The analytical results of the current test configurations showed that the magnitude of the strain energy release rate and the mode-mixity varied widely along the delamination. front. Results for the more curved specimen with a delamination at interface 1 are shown in Figure 6. The peak value for strain energy release rate occurs at a point along the delamination boundary measuring $7^{\circ}$ (and $187^{\circ}$ ) from the $\mathrm{X}$-axis of the specimen as described in the sketch. The results for panels with a delamination at interface 1 but with different curvatures looked similar with peaks occurring at angles between $7^{\circ}$ and $10^{\circ}$. The strain energy release rate values for all interface 2 configurations peaked at a location $21^{\circ}$ from the $\mathrm{X}$-axis. The mixed-mode ratio around the delamination front varied between $50 \%$ and $100 \%$ shear, and small increments in position along the delamination front could be associated with significantly large changes in mixed-mode ratio. The large variation in the mode mixture occurred where the Mode I and Mode II components become so small that a small Mode III component became dominant. Outside the Mode III dominated regions, the mode ratio was more stable and only varied between $60 \%$ and $85 \%$ shear. The mixed- mode ratio was around $70 \%$ shear when the strain energy release rate reaches its peak, so the critical fracture toughness for delamination growth was around $0.3 \mathrm{~kJ} / \mathrm{m}^{2}$ as shown in Figure 2.

A load-strain curve from a compression test is shown in Figure 7 along with the FE prediction. The two results compared very well until the delamination began to propagate. After this point, there was a slight divergence in the predicted stiffness since this $\mathrm{FE}$ analysis did not model delamination growth. To accurately make predictions beyond this point, a progressive damage model would be needed. Neither the FE prediction nor the experimental results showed

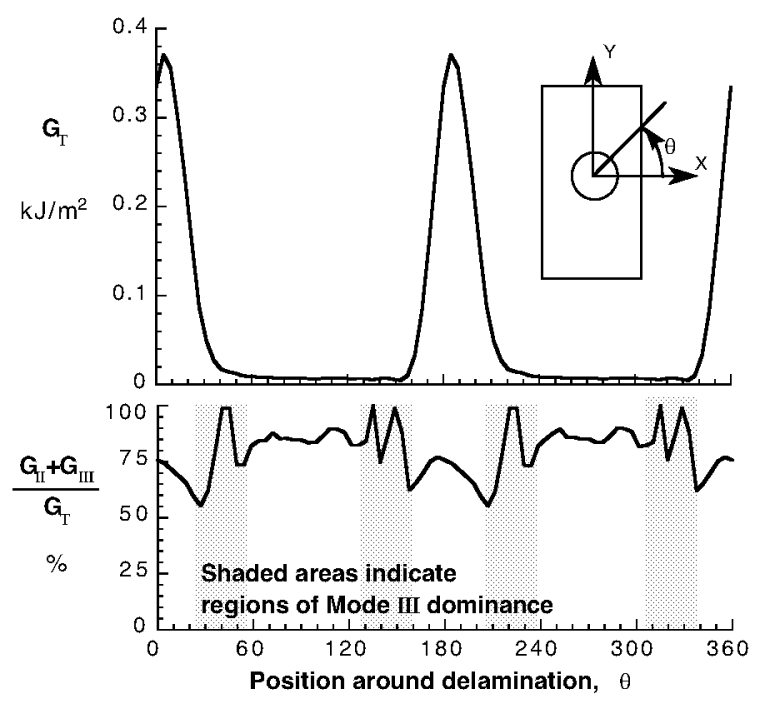

Figure 6. Typical variation in strain energy release rate (more curved|interface 1). 


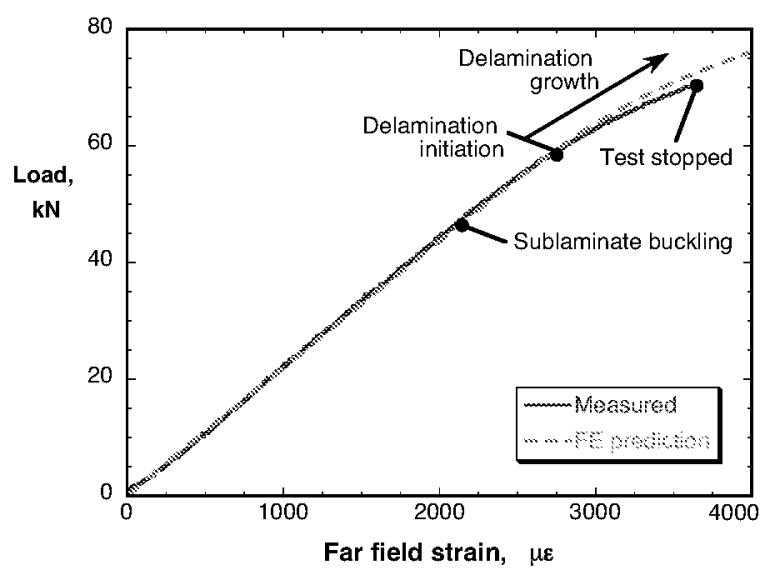

Figure 7. Typical load vs. strain results.

significant stiffness change in the load displacement curve when sublaminate buckling occurred indicating that the stiffness degradation due to this damage was minor.

The loads at which delamination buckling were observed are compared with predictions from the FE analysis in Figure 8 for each of the different test specimen configurations. The $\mathrm{FE}$ results were scaled to account for the analysis only modeling the 114-mm unsupported width of the test specimen while the total loaded width was $123-\mathrm{mm}$. The response of the test specimen was fairly linear up to failure, as shown in
Figure 7. Because of this, the global strain at failure approximately scaled with the critical load. The approximate level of critical strain can be read on the right hand axis of Figure 8 . The approximate critical global strain was within $8 \%$ of the true values for all data presented here. In Figure 8, the scatter in the buckling load values from the three replicate tests was significant. The coefficient of variation averaged $23 \%$. The FE analysis was not able to accurately predict the buckling loads of the panel with the worst correlation occurring in the flat panels. Since buckling is an instability phenomenon, it is greatly affected by seemingly small changes such as minor variation in the alignment of the specimen, small imperfections in the specimen surface, or degree of the edge constraint. Buckling of the test specimen would also have been delayed if a slight adhesion existed between the Teflon film and the composite. Even a slight adhesion between sublaminates could have provided enough support to cause a significant difference in sublaminate buckling load, and this effect was not represented in the $\mathrm{FE}$ analysis. This sensitivity to minor differences leads to the scatter and the difficulty in consistently modeling this phenomenon. As the curvature of the specimen increased, the sublaminate buckling loads were predicted to increase because of the increased stability of a shell structure. The measured buckling load did not show this trend as clearly. The buckling loads in the more curved panel did consistently increase, but the buckling loads of the

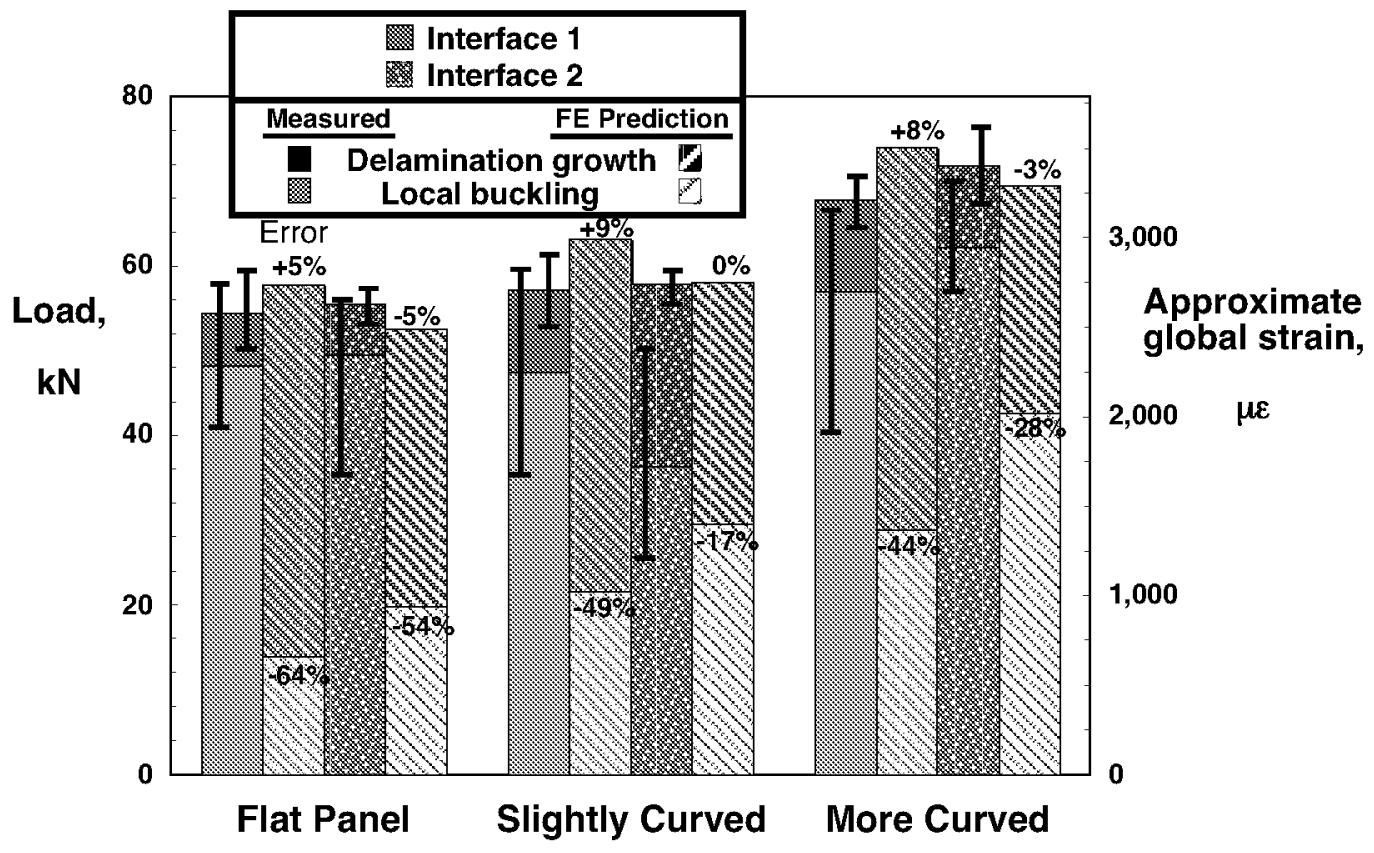

Figure 8. Comparison of experimental and analytical results for sublaminate buckling and delamination growth. 
slightly curved panel remained the same or decreased. One explanation for this unexpected behavior in the slightly curved panels would be that these specimens were fabricated on a convex tool which placed the thinner sublaminate on the bag side of the panel instead of on the tool side. This would cause this sublaminate to be less uniform than in the flat or more curved panels which could have lowered the sublaminate buckling load for the slightly curved panels.

The buckling load at interface 2 was predicted to be higher than at interface 1 because interface 2 was deeper in the laminate and therefore the sublaminate was thicker and more stable. The measured values demonstrated this effect but to a lesser degree than expected in both the flat and the more curved panel. The slightly curved panel again did not behave as expected with the interface 2 results being significantly less than expected. This could be due to a higher degree of imperfection as described earlier for the slightly curved specimen but would not explain why the interface 1 specimen did not show the same drop. No specific defects in the slightly curved interface 2 specimens were observed to explain this anomaly.

The measured loads when delamination growth initiated was much more consistent among replicate tests than the buckling loads were and agreed fairly well with the FE analysis predicted values. The average coefficient of variation was only $5 \%$ and the $\mathrm{FE}$ analysis results always agreed within $10 \%$. The FE analysis predicted values higher than the experimental result as often as it predicted lower values. The FE analysis predicted a $30 \%$ increase in load for delamination growth as the panel curvature increased from flat to the more curved panel. Measured values demonstrated a slightly lower increase in load (around 20\%) but captured the trend fairly well. The experimental results, however, did not show any significant increases from the flat to the slightly curved panel while the analysis predicted a $10 \%$ increase. This relatively small increase could have been masked by the scatter in the test results.

For the two interfaces tested, the deeper location (interface 2) was always predicted to grow at a lower load than the ones with a more shallow delamination location (interface 1). The predicted lower load for growth of the deeper delamination was contrary to the effect that would be predicted if the composite were homogenous. This effect in composites were created because the sublaminate had a ply stacking sequence of $(-45 /+45 / 90 / 0)$ when the delamination interface was at interface 1 which causes an extension/bending coupling that tends to reduce the Mode I strain energy release rate. The effect was reduced when the delamination was at interface 2 because the sublaminate ply stacking sequence $(-45 /+45 / 90 / 0 /-45)$ had the same top and bottom plys. The lower Mode I component at interface 1 not only decreased the total strain energy release rate but also reduced the mixed-mode ratio and, therefore, the critical fracture toughness (see Figure 2). The decreased Mode I component therefore caused the predicted load for delamination growth to be higher when the delamination was at interface 1 than when it was at interface 2. The experimentally determined loads for delamination growth did not show this predicted trend. In the tests, the delamination load consistently increased as the delamination interface was moved from interface 1 to interface 2 . This increase was negligible in the flat and slightly curved panels but was as high as $6 \%$ in the more curved panel. In no case did the predicted drop of $6 \%$ to $9 \%$ occur. One explanation for why the FE analysis did not accurately predict this subtle change would be that the delamination occurred between different combinations of plies at the two different interfaces. Studies have shown that the fracture toughness can be affected by the ply orientation above and below the delamination $^{19}$.

Even though the FE analysis was not able to capture the effect caused by changing the interface, it did produce, in all cases, fairly accurate predictions of load for delamination growth. It is surprising that the analysis predicted the load for delamination growth fairly accurately when it did not accurately predict the load for sublaminate buckling which occurred first. This inconsistency may be explained by realizing that the buckling response is an instability phenomenon and difficult to predict because of the reasons explained earlier. The linear buckling analysis clearly was insufficient for capturing the sublaminate buckling load. Once sublaminate buckling occurred, each panel deformed into a stable buckled state that the nonlinear analysis was able to predict accurately. The predicted buckled shape at the point of delamination growth is shown to compare well with measured values in Figure 9. From the buckled state, the delamination grew in a stable manner, and therefore, it was a phenomenon that could be more consistently reproduced in both test and analysis.

The current FE analysis did not model delamination growth beyond initiation, but progressive damage modeling techniques are being developed for delamination growth ${ }^{20-22}$. The tests conducted in this study were able to monitor delamination growth as well as determine the shape of the delamination under a fully 3-dimensional stress state. It is hoped that these results may be used in the future to verify the accuracy of some of these progressive models. The progression of delamination growth for one test specimen of each configuration is shown in Figure 10. $\mathrm{X}$-rays that document the shape of the delamination when the test was stopped are presented along with delamination growth results. The final size of the delamination is not of particular significance because 


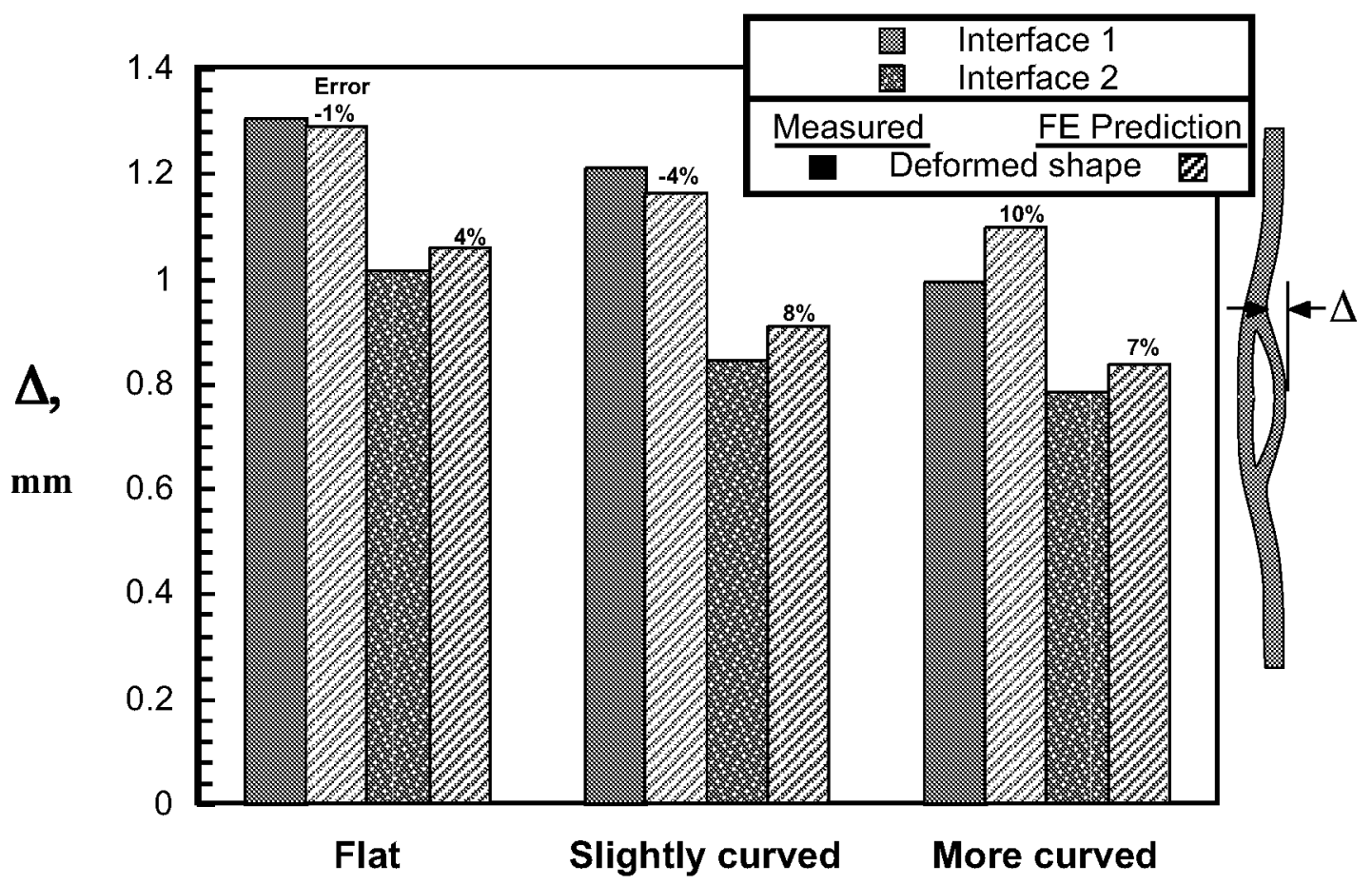

Figure 9. Comparison of buckling deformation measurements to FE analysis predictions.

the point at which each test was stopped was somewhat arbitrary. An accurate progressive model should however predict the onset of delamination, the rate of growth with additional loading, and the shape of the developing delamination.

\section{Concluding Remarks}

The growth phenomenon of a postbuckled delamination in a curved shell has been studied. The strain energy release rates determined from the shell model were compared to a mixed-mode fracture toughness failure criterion to predict initiation of delamination growth. The nonlinear analysis consistently predicted the load for delamination growth within $10 \%$ of the values measured from tests. These tests were conducted on flat and curved panels with radii of $762-\mathrm{mm}$ and $381-\mathrm{mm}$. Each panel had an initial circular delamination placed at one of two different interfaces within the laminate. The linear buckling analysis did not predict the load for delaminated sublaminate buckling very accurately. The experimental scatter in the measured buckling load was high because of the large effect of minor inconsistencies between otherwise replicate tests. Once the delamination buckled, it buckled into a fairly stable mode shape that could be modeled well. A stereo imaging system was used to determine the full-field out-of-plane deformation of the specimen. This measurement was used to determine initiation of delamination growth and to track delamination propagation. The size and shape of the final delaminated region was recorded using radiographic techniques. The two measurements agreed well and these results may be used to validate emerging progressive damage modeling techniques in the future.

\section{References}

${ }^{1}$ Naganarayana, B. P. and S. N. Atluri, "Computational Model for Analysing Interactive Buckling and Delamination Growth in Composite Structures," Sadhana Academy Proceedings in Engineering Sciences, Vol. 21, pp. 547-575, 1996.

${ }^{2}$ Zhang, X. and S. Yu, "An Analysis of Axisymmetric Buckling and Growth of Circular-shaped Delamination," Acta Mechanica Solida Sinica, Vol. 9, pp. 201-209, 1996.

${ }^{3}$ Krüger, R., S. Rinderknecht, C. Hänsel, and M. König, "Computational Structural Analysis and Testing: An Approach to Understand Delamination Growth," Key Engineering Materials, Vol. 120-121, pp. 181-202, 1996.

${ }^{4}$ Peck, S. O. and G. S. Springer, "Compression Behavior of Delaminated Composite Plates," NASA CR 184816, 1989.

${ }^{5}$ Yin, W. L. and K. C. Jane, "Refined Buckling and Postbuckling Analysis of Two-Dimensional Delaminations," presented at Recent Developments in Buckling of Structures; ASME 


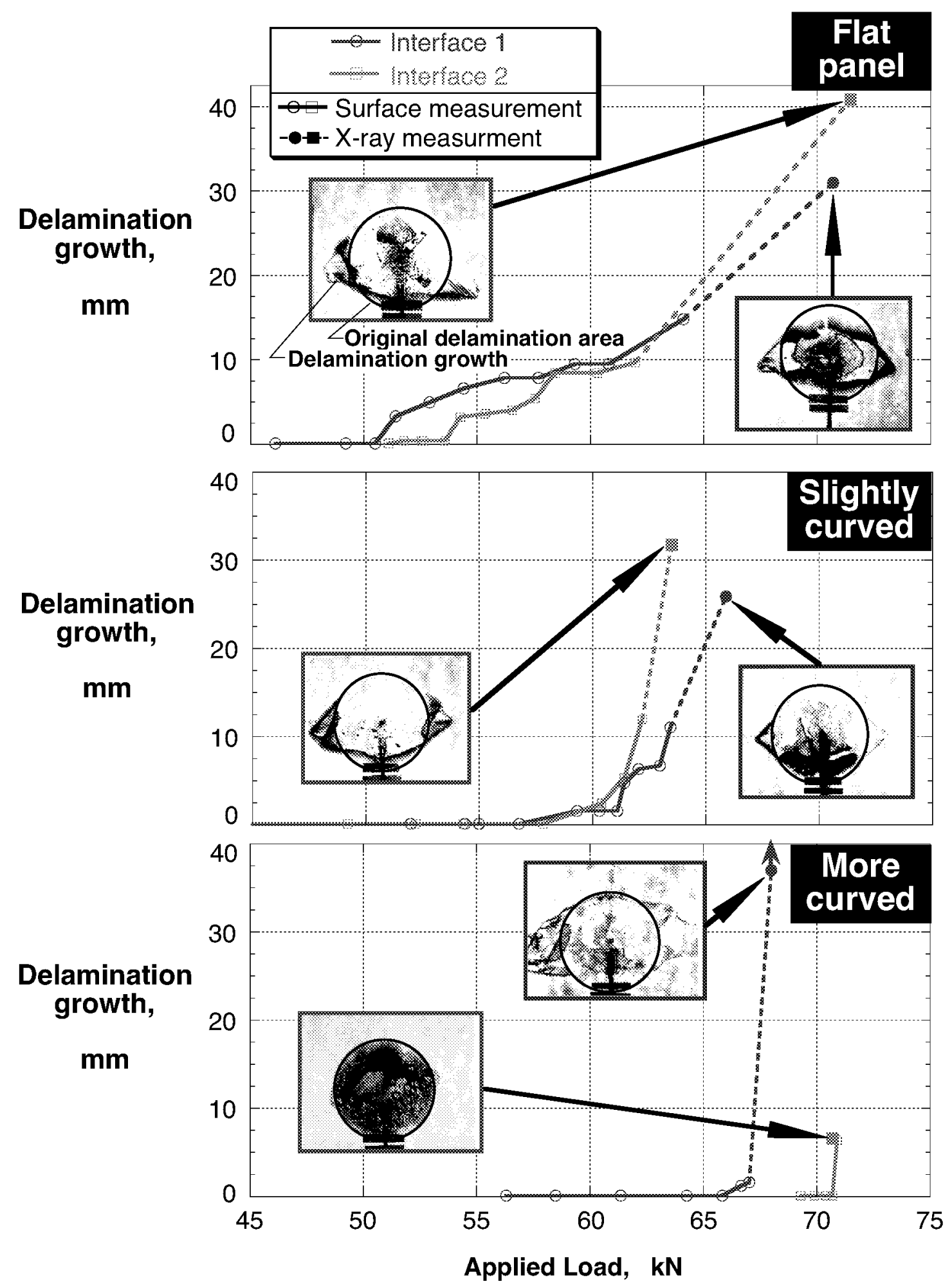

Figure 10. Delamination propagation records with $\mathrm{X}$-rays of final delamination sizes. Winter Annual Meeting, San Francisco, CA, 1989. 
${ }^{6}$ Whitcomb John, D., "Three-Dimensional Analysis of a Postbuckled Embedded Delamination," NASA TP 2823, pp. 1-24, 1988.

${ }^{7}$ Rybicki, E. F. and M. F. Kanninen, "A Finite Element Calculation of Stress Intensity Factors by a Modified Crack Closure Intergral," Engineering Fracture Mechanics, Vol. 9, pp. 931-938, 1977.

${ }^{8}$ Wang, J. T., I. S. Raju, and D. W. Sleight, "Composite Skin-Stiffener Debond Analysis Using Fracture Mechanics Approach with Shell Elements," Composites Engineering, Vol. 5, No. 3, pp. 277296, 1995.

${ }^{9}$ Glaessgen, E. H., W. T. Riddell, and I. S. Raju, "Effect of Shear Deformation and Continuity on Delamination Modeling with Plate Elements," AIAA-98-2022, 1998.

${ }^{10}$ Rinderknecht, S. and B. Kröplin, "A Finite Element Model for Delamination in Composite Plates," Mechanics of Composite Materials and Structures, Vol. 2, pp. 19-47, 1995.

${ }^{11}$ Pradhan, S. C. and T. E. Tay, "Three-dimensional Finite Element Modeling of Delamination Growth in Notched Composite Laminates Under Compression Loading," Engineering Fracture Mechanics, Vol. 60, No. 2, pp. 151-171, 1998.

${ }^{12}$ ABAQUS/Standard - User's Manual - Version 5.6, Vol. II: Hibbitt, Karlsson \& Sorensen, Inc., 1996.

${ }^{13}$ Walker, T. H., L. B. Ilcewicz, D. R. Polland, and C. C. Poe, Jr., "Tension Fracture of Laminates for Transport Fuselage, Part II: Large Notches," presented at Third NASA Advanced Composite Technology Conference, NASA CP 3178, 1992.

14"Standard Test Method for Mixed Mode I-Mode II Interlaminar Fracture Toughness of Unidirectional Fiber Reinforced Polymer Composite," in Annual Book of ASTM Standards 2001, Vol. 15.03: ASTM International, pp. 392-403, 2001.

${ }^{15}$ Reeder, J. R., "An Evaluation of Mixed-Mode Delamination Failure Criteria," NASA TM 104210, Febuary, 1992.

${ }^{16}$ Gong, X.-J. and M. Benzeggagh, "Mixed Mode Interlaminar Fracture Toughness of Unidirectional Glass/Epoxy Composite," in Composite Materials: Fatigue and Fracture-Fifth Volume, ASTM STP 1230 , R. H. Martin, Ed., American Society for Testing and Materials, Philadelphia, pp. 100-123, 1995.

17"Standard Tests for Toughened Resin Composites," NASA RP 1092, 1982.

${ }^{18}$ Helm, J. D., "Improved Three-Dimensional Image Correlation for Surface Displacement Measurement," Optical Engineering, Vol. 35, pp. 1911-1920, 1996.

${ }^{19}$ Polaha, J. J., B. D. Davidson, R. C. Hudson, and A. Pieracci, "Effects of Mode Ratio, Ply Orientation and Precracking on the Delamination Toughness of a Laminated Composite," Journal of Reinforced Plastics and Composites, Vol. 15, pp. 141-172, 1996

${ }^{20}$ Goyal-Singhal, V. K., N. Jaunky, E. R. Johnson, and D. Ambur, "Intralaminar and Interlaminar Progressive Failure Analysis of Composite Panels," to be published in 43rd AIAA/ASME/ASCE/AHS/ASC Structures, Structural Dynamics, and Materials Conference, Denver, CO, 2002.

${ }^{21}$ Ireman, T., et al., "Damage Propagation in Composite Structural Elements-Coupon Experiments and Analyses," Composite Structures, Vol. 36, pp. 209-220, 1996.

${ }^{22}$ Dávila, C. G. and P. P. Camanho, "Decohesion Elements using Two and Three-Parameter Mixed-Mode Criteria," presented at American Helicopter Society Conference, Williamsburg, VA, 2001. 